\title{
Analysis of HER2 Gene Amplification Using Differential PCR in Breast Cancer Patients in Isfahan Province
}

\author{
Zohreh Hojati *, Zeinab Hallajian, Abolghasem Esmaeili, Majid Motovali-Bashi, Hosein Tabatabaeian \\ Genetics Division, Biology Department, Faculty of Sciences, University of Isfahan, Isfahan, Iran.
}

Received: 15 Aug 2014

Revised : 10 Oct 2014

Accepted: 2 Nov 2014

Corresponding Authors:

Zohreh Hojati

Associate Prof. in Human Molecular

Genetics and Genetic Engineering,

Genetics Division, Biology

Department, Faculty of Sciences,

University of Isfahan, Isfahan, Iran.

Phone: +98-3117932478

Fax: +983-117932456

E-mail: z.hojati@sci.ui.ac.ir

\begin{abstract}
Background: Amplification of HER2 is seen in $20-30 \%$ of breast cancer cases. Measurement of HER2 gene amplification appears to be of vital importance in planning the treatment schedule for patients with breast carcinoma. The aim of our study was to evaluate HER2 amplification status in malignant and benign breast tumors by differential PCR (dPCR).

Materials and Methods: The genomic DNA was extracted using the phenol/chloroform extraction procedure from 76 different breast tissues. Differential PCR was performed using the DNA samples isolated from fresh and paraffin- embedded breast cancer tissues. The relative copy number ratio of target gene (HER2) to control gene (INF- $\gamma$ ) was measured. dPCR products were then separated by electrophoresis using $2 \%$ agarose gel. The intensity of HER 2 and INF $\gamma$ bands were determined for each sample by ImageJ software.

Results: According to the ratio between the band intensity of HER2 to INF $\gamma$ in tumour and also normal samples, $7 \%$ and $26 \%$ rates of HER2 amplification were observed in benign and malignant samples respectively. The ratio showed a 2-5 fold increase in HER2 gene copy number for tissues with HER2 amplification; whereas, a one-fold increase was found in other samples.

Conclusion: Differential PCR provides a relatively rapid and inexpensive technique to assess the HER2 gene amplification, especially alongside immunohistochemistry as a routine assessing method.
\end{abstract}

Keywords: HER2 amplification; Breast cancer; Differential PCR

Please cite this article as: Hojati Z, Zeinab Hallajian, Esmaeili A, Motovali-Bashi M, Tabatabaeian H. Analysis of HER2 Gene Amplification Using Differential PCR in Breast Cancer Patients in Isfahan Province. Res Mol Med. $2014 ; 2$ (4): 12-17

\section{Introduction}

The HER2 gene, also known as c-ERBB2, is a member of the erbB family located on chromosome 17 (q21-22) and encodes a $185 \mathrm{kDa}$ transmembrane protein (1-3). HER2 gene frequently undergoes amplification and overexpression in breast cancer cases $(4,5)$, leading to disease recurrence and reduced overall survival (6-9). Human breast tumors have different behaviors among HER2 gene copy number ranges of $1,2-5,5-20$, and $>20$. HER2 amplification and protein overexpression are strongly correlated with node-positive breast carcinomas and overall reduction in disease-free interval $(3,10)$. In addition, several studies have found HER2 gene amplification as a marker of appropriate response chemotherapy agents, but resistant to endocrine therapy (11). Furthermore, it has been demonstrated that only HER 2 -amplified breast cases are sensitive to Trastuzumab (an anti-HER2 monoclonal antibody) (12). Thus, measurement of HER2 gene amplification appears to be crucial in planning the treatment schedule for patients with breast carcinoma. There are different methods for detection of gene amplification, including Southern hybridization; Polymerase Chain Reaction (PCR) (competitive differential or real time) or Fluorescence In Situ Hybridization (FISH) (13). Microgram quantities of high quality DNA is required to use on southern blot or dot blot hybridization methods, lasting several days to obtain the results. Tumor samples are usually obtained either by biopsy (or aspiration), or by micro- 
section from paraffin-embedded archival tissues; therefore, it is not easy to get enough amount of DNA, in order to perform southern blot or dot blot hybridization. Real-time PCR is a very accurate and useful method for detection of gene amplification, however, it has two main disadvantages including the cost of the test, which is substantially higher than conventional PCR, and the need for professionally trained real-time PCR analyzers, which are currently beyond the means of many laboratories (14). Differential PCR (dPCR) is a powerful method which is performed quickly, and could be applied to propagate DNA from small amounts of samples. Indeed, dPCR is a semi-quantitative assay for the coamplification of a target and a reference gene in the same reaction tube (6). This technique is capable of detecting amplification in specific target genes as low as two-fold (15). dPCR-based detection of gene amplification has been demonstrated for several oncogenes (16).

The semi-quantitative level of the target gene amplification is seen by the ratio between the intensity of the two PCR product bands visualized on the electrophoresis gel. The relative ratio of interest target gene to the single copy reference gene can be calculated with a suitable software or gel densitometry system. In this study, reliable measurement of HER2 amplification was carried out followed by the optimization of two genes (HER2 and INF- $\gamma$ ) co-amplification. HER2 gene amplification frequency was analyzed in 71 DNA samples extracted from breast tumour specimens in Isfahan province, Iran. This study describes a simple, robust, and highly sensitive differential Polymerase Chain Reaction (PCR) as a method for detecting HER2 amplification in a routine pathology laboratory.

\section{Materials and Methods \\ Tissue}

Tumor samples were immediately stored in liquid nitrogen after tissue incision in surgery and then stored at $-70{ }^{\circ} \mathrm{C}$. $0.1-0.5 \mathrm{~g}$ of the frozen tissue specimens were disrupted using mortar and pestle along with liquid nitrogen and then homogenized using appropriate syringe. The genomic DNA was extracted using the phenol/chloroform extraction procedure (17). DNA concentration and quality of the extracted DNA was measured by spectrophotometer and gel electrophoresis, respectively. DNA was also extracted from archival formalin-fixed and paraffinembedded tissues, although an extra step of xylene extraction was required for these specimens. The removal of xylene was carried out as follow: the tissues was fixed in $10 \%$ buffered formalin for $24 \mathrm{~h}$ at room temperature and then processed according to routine pathological procedures. A microtome was used in order to make several $8-10 \mu \mathrm{m}$ cryosections of 5-10 mm sections of these tissues (about 5-10 sections). These tumor sections were then soaked in $1 \mathrm{ml}$ of xylene for $5 \mathrm{~min}$, and spun for $5 \mathrm{~min}$ at 13000 $\mathrm{rpm}$. The pellet was washed three times with $1 \mathrm{ml}$ of ethanol and spun for $5 \mathrm{~min}$ at $13000 \mathrm{rpm}$. The supernatant was discarded and the pellet was dried for at least $30 \mathrm{~min}$ then dissolved in a $5-20 \mathrm{ml}$ of water (16). All DNA samples were diluted to the same concentration of $50 \mathrm{ng} / \mu \mathrm{l}$.

\section{PCR Primers}

The sequences of the HER2 and INF- $\gamma$ genes were achieved from NCBI nucleotide database. The Oligo 7 software was used to design and also check the specificity of the primer sets with the following sequences: HER2 forward primer: 5'-CCTCTGACGTCCATCATCTC-3' and HER2 reverse primer: 5'ATCTTCTCGTGCCGTCGCTT-3', amplifying a 100 bp fragment of HER2 gene exon. INF- $\gamma$ forward primer: 5'-TCTTTTCTTTCCCGATAGGT-3' and INF- $\gamma$ reverse primer: 5'-CAGGGATGCTCTTCGA CCTC-3', amplifying a 150 bp fragment the interferon $\gamma$ gene exon (1).

\section{PCR Conditions}

DNA amplification was carried out in duplicate for all samples in the Eppendorf Mastercycler AG22331 PCR device. Each 25 reaction mixture contained $2 \mu 1$ of each primer (50 pmol), $2.5 \mu$ of $T a q$ polymerase buffer, $2 \mu \mathrm{l}$ of DNA (100 ng), and $16 \mu \mathrm{l}$ of PCR water. Two control samples that contained all the reagents but no target DNA were included with each batch. The reaction mixtures were prepared and kept on ice until the heating block of the thermal cycler reached the denaturation temperature $\left(94^{\circ} \mathrm{C}\right)$. The PCR amplification was carried out at $94{ }^{\circ} \mathrm{C}$ for 10 minutes and then subjected to 35 amplification cycles of 1 minute at $94{ }^{\circ} \mathrm{C}, 1$ minute at $58.4{ }^{\circ} \mathrm{C}$, and 1 minute at $70{ }^{\circ} \mathrm{C}$. These steps were followed by a final extension at $72{ }^{\circ} \mathrm{C}$ for 7 minutes.

\section{Differential PCR}

Amplification products were separated by electrophoresis using a $2.5 \%$ metaphor agarose gel, stained with ethidium bromide and visualized by ultraviolet illumination. The gel images were captured using a CCD camera linked to an image processing system. The intensities of the HER2 and INF- $\gamma$ bands were determined for each specimen by the imageJ software.

The results were expressed as a ratio: intensity of the HER 2 band/intensity of the INF- $\gamma$ band. The determined ratios for the tumor samples were converted into a measure of gene amplification. In this study, the 
values of 2 or more (mean normal range $+2 \mathrm{SD}$ ) were considered as the cut-off point for amplification.

\section{Statistical analysis}

Data analyses were carried out in SPSS version 19.0 (SPSS Inc., Chicago, III., USA). A P value of less than 0.05 was considered to indicate statistical significance. The association between HER2 amplification in benign and malignant samples was measured using Fisher's exact test. The $\chi^{2}$ test was applied to investigate the relation between tumor type and gene amplification.

\section{Results}

Differential PCR was performed for seventy one malignant and benign breast cancer cases. Five normal breast tissues were also included in this study. In next step, 100 and $150 \mathrm{bp}$ PCR products were resolved clearly using $2.5 \%$ metaphor agarose. In all normal samples the intensity of the INF- $\gamma$ band was greater than that of the HER2 band. Each sample was analyzed at least twice and each replicate gave concordant results. The intensity ratios of 100 to 150 bp bands were calculated. The ratio 1 to 2.0 indicates the absence of any gene amplification. On the other hand, the intensity ratio greater than 2 indicates the gene amplification. All DNA samples isolated from forty three malignant breast cancer tissues were analyzed for HER2 amplification. In samples with no HER2 amplification which constituted the majority of cases, the ratio of target to the control gene was almost 1 , while this value was between 2 to 6 for the tissues showing which implies HER2 gene amplification (Figure 1).

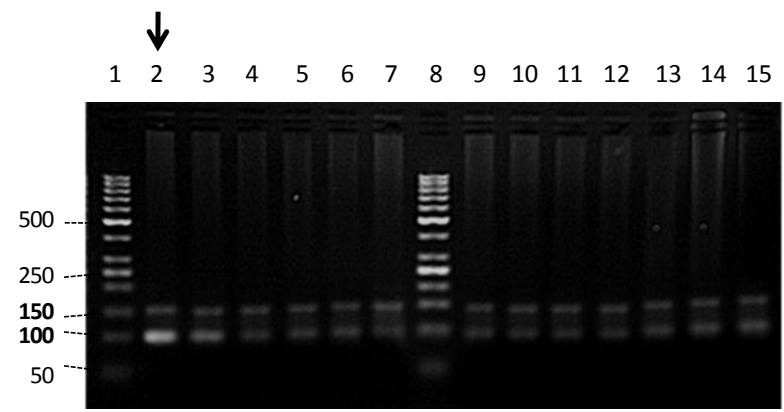

Figure 1. Analysis of HER2 amplification by differential PCR in malignant breast cancer tissues.

A $2.5 \%$ agarose gel was used for separation of the PCR products. The lanes are as follows: lanes 10 and 11: normal breast tissues as controls. Lanes 2, 3, 15: three breast tumors with HER2 amplification. The relative copy number of target gene to control gene as identified by ImageJ is 2 for lane 15, 3 for lane 3 and 5 for lane 2. Lanes 4-7, 9 and 12-14: breast tumors with no HER2 amplification. Lane 8: 50 bp DNA ladder. The arrow indicates the sample with highest copy number of HER2 gene.

According to the electrophoresis gel analyses using
Image J software, 32 out of $43(\sim 74 \%)$ malignant samples had a normal HER2 copy number, and 11 out of $43(\sim 26 \%)$ showed HER2 amplification (Figure 2). The distribution of HER2-amplified samples based on categories of malignant breast tumors is listed in Table 1. From twenty eight benign tumor samples analyzed in this study, two specimens (7\%) showed HER2 amplification (Figure 3).

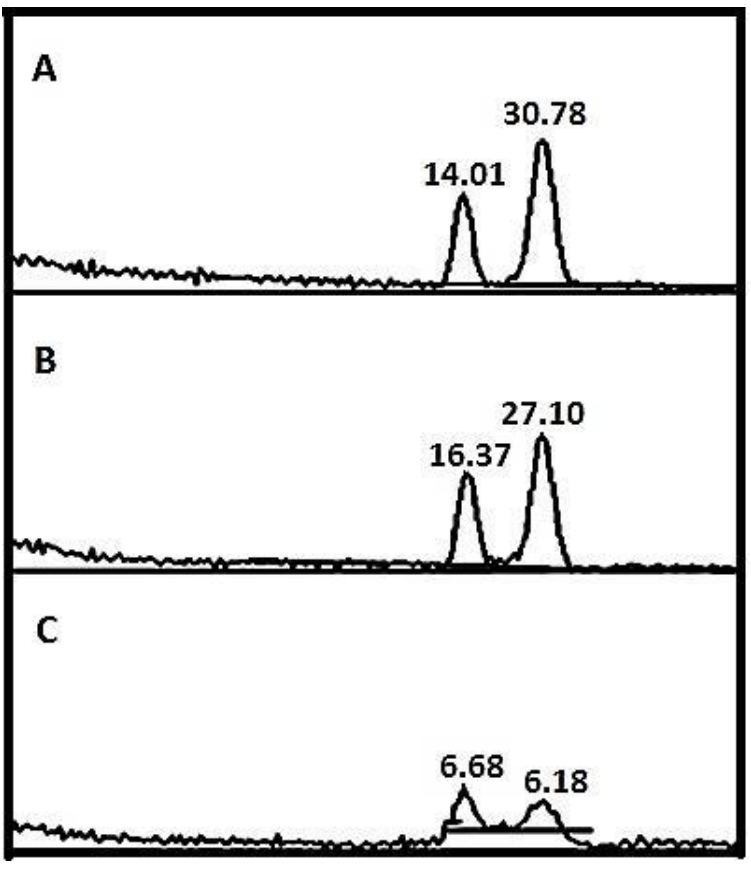

Figure 2. Analysis and identification of HER2 amplification in malignant breast cancer tissues using imageJ software.

After performing PCR and gel electrophoresis, the intensity of each band was analyzed by ImageJ for determining the copy number of the HER2 gene in each individual sample. A. A sample with HER2 amplification (measured intensity is 2.2 ). B. A sample with no HER2 amplification (measured intensity is 1.7). C. A sample with no HER2 amplification (measured intensity is 0.9 ).

A summary of the histopathologic findings is presented in Table 2 .

Table 1. Summary of the tumors with HER-2/neu amplification.

\begin{tabular}{lll}
\hline Malignant TT $^{*}$ & No & No of HER-2/nеи $\mathrm{A}^{* *}$ \\
\hline Ductal grade 1 & 5 & 0 \\
Ductal grade 2 & 14 & 6 \\
Ductal grade 3 & 4 & 2 \\
Lobular & 10 & 1 \\
Others & 10 & 1 \\
Total & 43 & 10 \\
\hline
\end{tabular}

* TT: tumor type

** A: amplification

Fisher's exact test showed a significant difference in 
HER2 gene amplification between benign and malignant groups $(\mathrm{P}=0.03)$. The chi-square test demonstrated a direct correlation between tumor type and gene amplification $(\mathrm{P}=0.04)$. Clearly, the frequency of gene amplification is higher in malignant tumor samples with ductal grade 2 and 3 (42.5\% and 50\%, respectively) (Table 1 ).

\section{Discussion}

Amplification is the only structural alteration of the HER2 gene observed in human cancers (18) and is found in $20-30 \%$ of breast tumors $(19,20)$. HER2 gene amplification results in an overexpression of $\mathrm{P} 185^{\mathrm{HER} 2}$ which is easily detected by immunohistochemistry (IHC) method on the cell surface of tumor cells. In 2001, Riou et al. analyzed HER2 amplification and P185 ${ }^{\mathrm{HER} 2}$ overexpression in 171 breast cancer patients and determined their impact on the risk of death and metastasis after a nearly 10-year follow-up. They showed that amplification-dependent HER2 overexpression is associated with an increased risk of death $(\mathrm{P}=0.01)$, while no relationship was found between HER2 overexpression with no amplification and the rate of mortality $(\mathrm{P}=0.54)$. Moreover, HER2 amplification was correlated with a higher risk of multifocal metastases $(\mathrm{P}=0.02)$, explaining the role of HER2 in cancer invasiveness (21). Therefore, measurement of HER2 gene amplification would be a better indicator comparing with its overexpression in breast cancer patients.

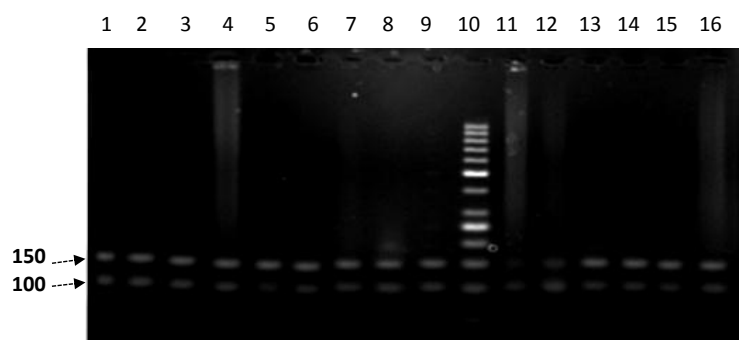

Figure 3. Determination of HER2 amplification by differential PCR in benign breast tissues.

A $2.5 \%$ agarose gel was used for separation of PCR products. The lanes are as follows: Lanes 1-7: Breast tumors with no HER2 amplification. Lane 11: a proliferative fibrocystic sample with HER2 amplification. Lanes 12: a Hyperplastic Hyperplasia sample with HER2 amplification, in which the relative copy number of the target gene to control gene was determined 3 for these two samples. Lane 10: $50 \mathrm{bp}$ DNA size marker.

The aim of this study was to present a robust differential PCR assay for detection of HER2 amplification in human DNA. In dPCR method, numerical results are generated by an image analysis system; therefore, this technique provides objective analysis of a molecular marker, making it a good candidate for development as a routine pathology test. The sensitivity of this technique and the small sizes of PCR products make the protocol amenable to the analysis of small amounts of degraded DNA (16). In this study, 11 out of $43(\sim 26 \%)$ breast tumors showed HER2 amplification, exhibiting low and medium levels (two to six folds) of HER2 amplification detected by ImageJ software. Twenty eight benign biopsies were also studied, showing 2 cases of HER2 amplification ( 7\%). In 1997, Jennings et al. reported the amplification of HER2 in $\sim 26 \%$ of breast tumor samples ${ }^{(6)}$ that is identical to outcome of this study. Despite this similarity, other studies using dPCR method found different outcomes. In 1999, Deng et al. observed HER2 amplification among $35 \%$ of their cases (22), which is consistent with our previously published paper reporting $35 \%$ rate of HER2 amplification (5). In three various studies the rate of HER2 amplification using differential PCR were $13.7 \%, 16.7 \%$, and $15 \%$, respectively (23-25).

Invasive breast cancer and/or atypical hyperplasia could be developed in some women with benign breast disease (BBD). In such cases histopathological predictions are not efficient and informative enough because of inter- and/or intra-observer variability, differences in pathologic criteria, and limitations in the quantity of tissue available for examination (26), therefore, detection of possible genetic alterations in BBD using molecular techniques could be considered as a promising method to improve risk prediction. These techniques may also be appropriate for rapid detection of gene amplification as an important parameter in determining a standard chemotherapeutic regimen.

Table 2. Histopathology diagnosis and HER-2/neu amplification status of the benign tissue specimens.

\begin{tabular}{lll}
\hline Benign TT $^{*}$ & No & No of HER-2/neu $\mathbf{A}^{* *}$ \\
\hline Proliferative Fibrocystic & 4 & 1 \\
Non-proliferative Fibrocystic & 3 & 0 \\
Calcification & 3 & 0 \\
Mastitis & 3 & 0 \\
Fibroadenoma & 4 & 0 \\
Fibrosis & 4 & 0 \\
Cystic & 4 & 0 \\
Hyperplastic Hyperplasia & 3 & 1 \\
Total & 28 & 2 \\
* TT: tumor type & & \\
** A: amplification & &
\end{tabular}

Moreover, amplification of HER2 in BBDs has also been considered as a sensitive biomarker of susceptibility for subsequent invasive breast carcinomas. Our findings about benign samples 
provide additional postulation that genetic alterations, including HER2 amplification, may be occurred as a relatively early event in the development of breast cancer.

The main drawback of $\mathrm{dPCR}$ is that this technique is a kind of end-point PCR which is an inefficient indicator of the real amount of initial target. In this semi-quantitative technique, obtained products are investigated in linear or plateau phases of polymerase chain reaction which is not a precise and appropriatestage for assessing gene expression comparing with exponential phase of amplification reaction used for quantitative studies in Real Time RT-PCR; altogether, make dPCR method less accurate.

The main sore point of this study was extraction of DNA from heterogenic tumor specimens. The probable contamination of tumor cells by normal cells (like blood vessels) can result in the dilution of HER2 positive tumor cells and thus may mask the amplification status of target genes. Using laser microdissection for separating normal cells is strongly suggested.

\section{Conclusion}

Differential PCR method can be used routinely and clinically as a rapid, cheap and easy PCR-based protocol for the assessment of gene copy number in both fresh and archival samples. It is especially recommended to be used along with golden standard technique of HER2 evaluation, i.e. IHC. These assessments are clinically useful to determine the therapeutic regimens as well as the biological characteristics of breast cancer.

\section{Acknowledgments}

This study was performed at the University of Isfahan and financially supported by the graduate Office of the University of Isfahan.

\section{Conflict of Interest}

The authors declare that they have no conflict of interest.

\section{References}

1. Goebel SU, Iwamoto M, Raffeld M, Gibril F, Hou W, Serrano J, et al. HER-2/neu Expression and Gene Amplification in Gastrinomas Correlations with Tumor Biology, Growth, and Aggressiveness. Cancer Res. 2002; 62(13):3702-10. PMID: 12097278 .

2. Osborne C, Wilson P, Tripathy D. Oncogenes and tumor suppressor genes in breast cancer: potential diagnostic and therapeutic applications. Oncologist. 2004; 9(4):361-77. PMID: 15266090 .

3. Wang S, Saboorian MH, Frenkel EP, Haley BB, Siddiqui MT, Gokaslan S, et al. Assessment of HER-2/neu Status in Breast Cancer Automated Cellular Imaging System (ACIS)-Assisted
Quantitation of Immunohistochemical Assay Achieves High Accuracy in Comparison With Fluorescence In Situ Hybridization Assay as the Standard. Am J Clin Pathol. 2001; 116(4):495-503. PMID: 11601134

4. Tabatabaeian H, Hojati Z. Assessment of HER-2 gene overexpression in Isfahan province breast cancer patients using real time RT-PCR and immunohistochemistry. Gene. 2013; 531(1):39-43. PMID: 24013082.

5. Hojati Z, Orangi E. HER-2/neu gene amplification assessment in breast cancer patients in Isfahan province by real time PCR, differential PCR and immunohistochemistry. Gene. 2012; 497(2):237-42. PMID: 22326523.

6. Jennings B, Hadfield J, Worsley S, Girling A, Willis G. A differential PCR assay for the detection of c-erbB 2 amplification used in a prospective study of breast cancer. Mol Pathol. 1997; 50(5):254-6. PMID: 9497915

7. Molland J, Barraclough B, Gebski V, Milliken J, Bilous M. Prognostic significance of c-erbB-2 oncogene in axilary nodenegative breast cancer. Aust N Z J Surg. 1996; 66(2):64-70. PMID: 8602816

8. Huang W, Reinholz M, Weidler J, Yolanda L, Paquet A, Whitcomb J, et al. Comparison of central HER2 testing with quantitative total HER2 expression and HER2 homodimer measurements using a novel proximity-based assay. Am J Clin Pathol. 2010; 134(2):303-11. PMID: 20660336

9. Grimm EE, Schmidt RA, Swanson PE, Dintzis SM, Allison KH. Achieving 95\% Cross-Methodological Concordance in HER2 Testing Causes and Implications of Discordant Cases. Am J Clin Pathol. 2010; 134(2):284-92. PMID: 20660333

10. Slamon DJ, Clark GM, Wong SG, Levin WJ, Ullrich A, McGuire WL. Human breast cancer: correlation of relapse and survival with amplification of the HER-2/neu oncogene. Science. 1987; 235(4785):177-82. PMID: 3798106

11. Motomura K, Koyama H, Noguchi S, Inaji H, Azuma C. Detection of c-erbB-2 gene amplification in nipple discharge by means of polymerase chain reaction. Breast Cancer Res Treat. 1995; 33(1):89-92. PMID: 7749137

12. Bilous M, Dowsett M, Hanna W, Isola J, Lebeau A, Moreno A, et al. Current perspectives on HER2 testing: a review of national testing guidelines. Mod Pathol. 2003; 16(2):173-82. PMID: 12591971

13. Hanna WM, Kahn HJ, Pienkowska M, Blondal J, Seth A, Marks A. Defining a test for HER-2/neu evaluation in breast cancer in the diagnostic setting. Mod Pathol. 2001; 14(7):677-85. PMID: 11455000

14. Stark D, Beebe N, Marriott D, Ellis J, Harkness J. Evaluation of three diagnostic methods, including real-time PCR, for detection of Dientamoeba fragilis in stool specimens. J Clin Microbiol. 2006;44(1):232-5. PMID: 16390978

15. Underwood M, Bartlett J, Cooke T. An improved method for semiquantification of gene amplification from archival material. PCR Methods Appl. 1994;4(3):178-84. PMID: 7580903

16. Hiyama E, Hiyama K, Yokoyama T, Fukuba I, Yamaoka H, Shay JW, et al. Rapid detection of MYCN gene amplification and telomerase expression in neuroblastoma. Clin Cancer Res. 1999; 5(3):601-9. PMID: 10100712 
17. Shi S-R, Datar R, Liu C, Wu L, Zhang Z, Cote RJ, et al. DNA extraction from archival formalin-fixed, paraffin-embedded tissues: heat-induced retrieval in alkaline solution. Histochem Cell Biol. 2004; 122(3):211-8. PMID: 15322858

19. Argiris A, Wang C-X, Whalen SG, DiGiovanna MP. Synergistic interactions between tamoxifen and trastuzumab (Herceptin). Clin Cancer Res. 2004; 10(4):1409-20. PMID: 14977844

20. Arteaga CL. Can trastuzumab be effective against tumors with low HER2/Neu (ErbB2) receptors? J Clin Oncol. 2006; 24(23):3722-5. PMID: 16847283

21. Riou G, Mathieu MC, Barrois M, Le Bihan ML, Ahomadegbe JC, Bénard J, et al. c-erbB-2 (HER-2/neu) gene amplification is a better indicator of poor prognosis than protein over-expression in operable breast-cancer patients. Int J Cancer. 2001; 95(4):266-70. PMID: 11400121

22. Deng G, Kim YS. Quantitation of erbB-2 gene copy number in breast cancer by an improved polymerase chain reaction (PCR) technique, competitively differential PCR. Breast Cancer Res Treat. 1999; 58(3):213-7. PMID: 10718483
18. Hynes NE, Gullick W. Therapeutic targeting of signal transduction pathways and proteins in breast cancer. J Curr Med Chem Anticancer Agents. 2006; 11(1):1-2. PMID: 12769778

23. Friedrichs K, Lohmann D, Höfler H. Detection of HER-2 oncogene amplification in breast cancer by differential polymerase chain reaction from single cryosections. Virchows Arch B Cell Pathol Incl Mol Pathol. 1993; 64(1):209-12. PMID: 7904515

24. López-Guerrero JA, Navarro S, Noguera R, Almenar S, Pellin $\mathrm{A}$, Vázquez $\mathrm{C}$, et al. Histological tumor grade correlates with HER2/c-erB-2 status in invasive breast cancer: a comparative analysis between immunohistochemical (CB11 clone and Herceptest), FISH and differential PCR procedures. Arkh Patol. 2002; 65(1):50-5. PMID: 12669615

25. Valerón PF, Chirino R, Fernandez L, Torres S, Navarro D, Aguiar J, et al. Validation of a differential PCR and an ELISA procedure in studying HER-2/neu status in breast cancer. Int $\mathbf{J}$ Cancer. 1996; 65(2):129-33. PMID: 8567106

26. Stark A, Hulka BS, Joens S, Novotny D, Thor AD, Wold LE, et al. HER-2/neu amplification in benign breast disease and the risk of subsequent breast cancer. J Clin Oncol. 2000; 18(2):267-74. PMID: 10637239 